\title{
PROCESSES OF CREOLE FORMATION AND RELATED CONTACT- INDUCED LANGUAGE CHANGE
}

\author{
Donald Winford \\ The Ohio State University
}

\section{Introduction}

The relationship between the processes of change involved in creole formation and those involved in other outcomes of language contact has long been of interest to scholars in the field of contact linguistics. As early as the nineteenth century, Schuchardt and other pioneers of creole studies such as Coelho (1880-6) and Hesseling (1897) explored issues such as the relationship between creole formation and first and second language acquisition, and the role of substrate influence and universals in creole formation. Moreover, the processes of creole formation and the typological characteristics of creoles have long been a point of reference and comparison for other outcomes of language contact. During the last four decades of the $20^{\text {th }}$ century, creole linguistics in many ways dominated the emerging field of contact linguistics, and it was commonplace for scholars to extend the term "creolization" to a variety of contact languages that arose under very different sociohistorical circumstances from those that produced creoles.

For instance, Gumperz \& Wilson (1971) described the well-known situation of language contact between Urdu, Kannada and Marathi in Kupwar, India, suggesting that the Kupwar varieties have processes of reduction and convergence "suggestive of pidginization and creolization" and that

the present state of the varieties is creole-like, in that one finds grammatical structure and lexical shape pointing to different sources, quite like the stereotype of a pidgin or creole as the words of one language used with the grammar of another (1971:165).

Similarly, Southworth (1971) suggested that,

whether or not Marathi qualifies as a true creole, its present characteristics are probably the result of a prolonged process of mutual adaptation between an Aryan language and a local pidgin-creole (or more likely, a series of pidgin-creoles) (1971:268).

Finally, Bailey \& Maroldt (1977) argued that Middle English emerged as a result of processes of creolization involving influence from Old Norse and Norman French on Anglo-Saxon. They note that Middle English displays features typically associated with creoles, such as analyticity, simplification of bound morphology, and the use of Anglo-Saxon words in French functions. They describe creolization in a very broad sense, as follows: 
By creolisation, the authors wish to indicate gradient mixture of two or more languages; in a narrow sense, a creole is the result of mixing which is substantial enough to result in a new system, a system that is separate from its antecedent parent systems. (1977:21).

In short, "creolization" became a cover term for different types of language mixture in a variety of contact situations.

In this paper, I explore the relationship between creole formation and other outcomes of contact induced change and argue that in many respects the comparisons that earlier scholars made between the two have a sound basis in terms of the processes of change that produced such outcomes. Such processes include various forms of 'simplification', varying degrees of structural convergence, the reanalysis of lexical items of one language in terms of the grammatical categories of another, and various other phenomena that are due to internally and externally motivated change. Henceforth, I focus my attention only on those aspects of creole formation that result from the kind of crosslinguistic influence that has been referred to variously as 'substratum influence,' 'interference via shift,' 'transfer' and 'convergence.' I argue that such influence is part of a more general type of contact-induced change that is brought about by imposition, a transfer type that manifests itself in a wide variety of contact situations not traditionally treated as involving the creation of creoles.

Creolists now generally agree that creole formation represents a somewhat unusual type of group second language acquisition, and therefore shares much in common with other cases of "natural" second language acquisition in terms of the processes of restructuring that are involved. Significant progress has been made of late in understanding these processes, particularly as they relate to the role of substrate influence or 'transfer.' But it is not generally recognized that other situations of contact that lead to convergence across languages also manifest processes of change similar to those found in creole formation and second language acquisition. I refer in particular to cases of language attrition, in which a newly acquired L2 exerts influence on a speaker's original L1. Such situations are similar to cases of shift with respect to the fact that a dominant language - the L1 in cases of SLA or creole formation, and the L2 in cases of language attrition - affects the grammar of the less dominant language. I argue that the contact phenomena found in both of these types of situation result from the same kind of transfer type, namely, imposition.

In the following section, I explain the concept of imposition, which is one of the key elements in van Coetsem's $(1988,2000)$ framework for the analysis of contact-induced change. In section 3, I illustrate the workings of imposition in a variety of contact situations, including those that involve second language acquisition, and those that involve language attrition. In particular, I examine cases of structural convergence at various levels of grammatical structure, and demonstrate the similarity of such phenomena across these types of contact situation. In section 4, I discuss psycholinguistic approaches to these types of cross-linguistic influence in contemporary bilingual speech, and provide a brief overview of psycholinguistic models of bilingual language production. Studies of this type lend strong support to the claim that linguistic dominance, that is, the bilingual's degree of proficiency in his two languages, is a key factor in determining the nature and degree of crosslinguistic influence. This is quite compatible with the idea that imposition from the dominant language is responsible for the kinds of convergence phenomena we find in cases of second language acquisition and language attrition. I then discuss how psycholinguistic approaches can shed light on the role played by imposition in past historical situations that gave rise to creoles and related outcomes of language contact. In section 5, I discuss two linguistic models that have been proposed for the description and analysis of such phenomena in creole formation, namely, Lefebvre's (1998) Relexification model, and Myers-Scotton's (2002) Abstract Level Structure model. I argue that these models are compatible with van Coetsem's view of imposition, and shed some light on the mechanisms underlying this transfer type, and how they produce the kinds of contact phenomena found in creole formation, as well as in cases of language attrition. I further 
argue that these mechanisms are essentially psycholinguistic in nature, and can best be understood in the context of psycholinguistic models of bilingual speech production. Finally, I suggest how insights from such models can clarify our understanding of how imposition produces the kinds of convergence phenomena we find in creoles and related outcomes of contact-induced change.

\section{Imposition in Van Coetsem's framework}

The framework I employ here was introduced by van Coetsem $(1988,2000)$, who distinguishes between two types of cross-linguistic influence, or what he calls "transfer types", namely, borrowing and imposition. Since the latter term is less widely known or used than the former, some justification for its choice is in order. ${ }^{1}$ First, the term avoids the confusion caused by labels such as 'interference,' 'transfer,' and others that have been used in very different senses by different researchers. Second, the term is economical, in that it covers a range of types of contact phenomena that have been referred to by a variety of terms, including 'interference via shift,' 'indirect diffusion,' and 'substratum influence.' Third, the term describes a transfer type which is more general than usually acknowledged in the literature, and which is found both in situations of second language acquisition and language attrition. Finally, as will be argued below, the term 'imposition' and the type of agency associated with it are compatible with a psycholinguistic approach to the mechanisms of change that underlie this transfer type.

In both borrowing and imposition, there is a source language (SL) and a recipient language (RL). The direction of transfer of linguistic features is always from the SL to the RL, and the agent of transfer can be either the RL or the SL speaker. In the former case, we have borrowing (recipient language agentivity), in the latter, imposition (source language agentivity). Lexical borrowing is a typical example of the former kind of transfer, as illustrated in the many lexical items that have been adopted by English from various languages. Source language agentivity is exemplified in cases of second language acquisition, where learners transfer features of their first or primary language (the source language) into their version of the second (recipient) language.

A crucial criterion in distinguishing between borrowing and imposition is the notion of language dominance. As Van Coetsem (2000:84) explains, difference in linguistic dominance is the main criterion for distinguishing between RL and SL agentivity. In borrowing, the RL is typically the dominant language of the speaker, while in imposition, the SL is the dominant language. When we speak of dominance here, we are referring to linguistic dominance, that is, the fact that the speaker is more proficient in one of the languages in contact. This must be distinguished from social dominance, which refers to the political or social status of one of the languages. The socially dominant language may or may not be the linguistically dominant language of the speaker. This crucial distinction has been overlooked by scholars such as Johanson (2000, 2002), who also uses the term 'imposition,' to refer to contact-induced change that occurs when "speakers of a primary code insert or "carry over" copies of their own code into their variety of a dominant code" (2000:166). Unfortunately, Johanson appears to treat dominance as a purely social, rather than a (psycho-)linguistic notion. It is only the latter sense that is appropriate here. It is simply not the case that a socially dominant language is necessarily the linguistically dominant language of the speaker who initiates contact-induced change. In addition, of course, dominance relationships may change over time, both in the individual speaker and in the society at large. And such shifts in dominance may result in differences in the nature and direction of change in the languages in contact.

Differences between RL and SL agentivity are also related to what Van Coetsem (1988:25) calls the 'stability gradient' of language. This refers to the fact that certain components of a language, such as phonology, morphology and syntax, tend to be more stable and hence resistant to change,

\footnotetext{
${ }^{1}$ The term "imposition" had previously been used in a similar sense by scholars like Gass (1983:70); Milroy (1983:190) and Trudgill (1983:205).
} 
while others, such as vocabulary, are less stable and thus more amenable to change. The less stable nature of the lexicon explains why lexical borrowing tends to be much more common than structural borrrowing. In addition, borrowing usually has little if any effect on the grammar of the recipient language, which is dominant. In imposition, on the other hand, it is the source language grammar that is more stable and resistant to change. As the dominant language in this case, its grammatical features tend to be retained, and imposed on the RL, leading to significant structural change in the speaker's version of the latter.

Van Coetsem's approach is based on the conviction that language contact studies should focus on the mechanism of change, which is an individual phenomenon, and not just on the diffusion of change, which is a social phenomenon. The former has to do with the (psycho)linguistic processes that reside in individual minds, while the latter has to do with processes of diffusion, leveling and focusing (conventionalization) within speech communities, which are sociolinguistically motivated. This emphasis on the cognitive processes involved in contact-induced change is equally as important as the traditional concern with socio-historical and sociolinguistic aspects of contact. It allows for new connections to be made between purely structural (linguistic) approaches to contact and psycholinguistic models of plurilingual speech production.

In the following section, I discuss various examples of contact-induced changes that arose as the result of imposition. Change of this type generally falls under the umbrella of what has been referred to variously as "convergent development" (Weinreich 1953), "structural convergence" (Heath 1984:367), "indirect diffusion" (Aikhenvald 2002), "grammatical replication" (Heine \& Kuteva 2005:13), and so on. Henceforth I will use the term convergence to refer to these types of contact-induced changes. Convergence phenomena can arise in two very different situations of contact. First, there are cases of group SLA (including creole formation) - the situations that are typically associated with the transfer of L1 features and patterns into a newly acquired L2. But imposition can also take place in the opposite direction, when an individual or a gaaroup becomes more proficient in an L2 and then imposes its features on their original L1 or ancestral language. Such situations typically involve L1 attrition, with the L2 becoming the linguistically dominant language. It is situations of the latter type that have proven most controversial in debates about the scope and nature of structural borrowing.

\section{Imposition in cases of second language acquisition and attrition}

The processes of change typical of imposition are to be found in a wide variety of contact situations involving second language acquisition, as well as in situations of language attrition. The effects of imposition can be found at all levels of linguistic structure, from the phonetic/phonological to the level of discourse. Here, I focus on convergence at the level of morphosyntax and syntax.

\subsection{Imposition in second language acquisition}

Situations involving second language acquisition include classroom learning, language shift leading to the formation of 'indigenized' varieties of English and other languages, and creole formation. There is a vast literature documenting the types of changes that occur in the recipient language under such circumstances. I provide only a few illustrative examples here.

\subsubsection{Imposition of tense/aspect categories}

One of the most thoroughly described areas of morphosyntactic change in shift situations is the expression of tense/aspect categories. A well-known example of this is the influence of Irish Gaelic on certain tense/aspect categories of Irish English. For instance, the after perfect of the latter is clearly modeled on a similar category in the former, as the following examples illustrate (Harris 1984:319). 
(1) Irish English She's after selling the boat.

Irish Gaelic sá sí tréis an bád a dhíol
Be+nonpast she after the boat selling.
'She's (just) sold the boat.'

Sabban (1984:16) describes similar constructions in Hebridean English, which she ascribes to influence from Scottish Gaelic:

(2) I'm just after finishing my washing.

In Singapore English, the aspectual categories of completive perfect and experiential perfect, expressed by already and ever respectively, appear to be modeled on the corresponding categories of Chinese, expressed by le and guo respectively (Bao 2005). In the case of already and le, the parallels are quite subtle, since the interpretation of either can change depending on the aktionsart of the predicate involved. For instance, with non-statives, both items convey the sense of a completed action:

(3) I wash my hand already

(Bao:239)

'I (have) washed my hand'

(4) wǒmen chi le liúlián

We eat COMPL durian

'We ate durian'

With statives and habituals on the other hand, both already and le convey the sense of an inchoative:

(5) SingE a. The wall white already. (Bao:239)

'The wall (has) turned white/ *The wall was white'

Chineseb. qiáng bái le (Bao:242)

wall white COMPL

'The wall is whitened'

(6) SingE a. Last time John was a housing agent. Now he drive taxi for a

living already. (p. 241)

$\begin{array}{llllll}\text { Chineseb. } & \text { Zhāngsān } & \text { kāi ché móu shēng le } \\ & \text { Zhangsan } & \text { drive car for life } & \text { COMPL } \\ & \text { 'Zhangsan now drives for a living' } & & \end{array}$


Bao also demonstrates several other similarities between already and le on the one hand, and between ever and guo on the other. He concludes, with good reason:

Given the convergence in aspectual meanings between Singapore English and Chinese, we conclude that already and ever are English words which have been grammaticalized to express the perfective aspects derived from Chinese. (Bao:245)

As far as creoles are concerned, there is also a fairly extensive literature on the effects of imposition in the creation/evolution of TMA systems and other areas of morphosyntax.

For example, the Surinamese creoles all have a category of completive aspect that is conveyed by a marker that is formally similar to a main verb meaning 'finish' kaba (< Portuguese acabar 'finish').

$\begin{array}{llll}\text { (7) } & \text { SN } & \text { kownu doro kaba. } \\ & \text { DET } & \text { king arrive COMPL }\end{array}$

'The king has already arrived.'

Winford \& Migge (2007:84) argue that this category is modeled on the completive aspectual category of Gbe languages, as illustrated in the following example.

(8) Ajagbe àxòsu lo à, e vá ló vò.

king the TOP he come arrive COM

'As for the king, he has already come.'

Other Surinamese creole categories that show strong evidence of imposition from Gbe include the Perfective, Imperfective and Potential (Winford \& Migge 2007). The influence of substrate languages on creole tense/aspect categories has also been documented by Lefebvre (1998) for Haitian Creole, and Siegel (2000) for Hawai'i Creole English.

The cases described above, which involve the imposition of SL functions or categories on RL lexical items, have been referred to as instances of "contact-induced grammaticalization," which is a subtype of "grammatical replication" (Heine \& Kuteva 2005:13). There is a growing literature on these types of contact-induced change in a number of situations other than creole formation. See Heine \& Kuteva (2005), Aikhenvald (2002), and Johanson (2000) for more detailed overviews.

\subsubsection{Imposition of syntactic patterns}

What Heine \& Kuteva call "grammatical replication" under contact can also be found at the level of syntax, including patterns of word order, subordination, relativization, and so on.

\subsubsection{Imposition of word order}

Odlin (1990) discusses the transfer of basic word order patterns in several cases of group SLA, including Hawai'ian Pidgin English and Andean Spanish. In the latter, the SVO order of general Spanish is often replaced by an SOV pattern due to Quechua influence, as in the following example (Odlin 1990:103): 
(9) Y mi hermano aquí otro paloma hembra había chapado.

And my brother here another dove female had caught.

Another example of word order transfer is found in the pattern of relativization in some varieties of South African Indian English. Mesthrie \& Dunne (1990:35-37) discuss several examples of this. For example, speakers whose L1 is Hindi or a similar Indic language produce relative structures like the following:

(10) Which-one I put in the jar, that-one is good.

'The ones [i.e., pickles] I put in the jar are the best.'

This mimics the correlative construction with a pre-nominal relative clause that is found in Indic languages:

(11) je

vepari

mari sathe avyo, te

vepari

CORRELAT. businessman me with came that businessman

harilal ka

bhäi che

Harilal of

brother is

'The businessman who came with me is Harilal's brother'

[Lit: Which businessman came with me, that businessman is Harilal's brother]

\subsubsection{Serial verb constructions}

A final example of the transfer of syntactic strategies is the emergence of serial verb constructions in situations of SLA and creole formation. For instance, Singapore English employs directional SVCs modelled on those of Chinese:

(12) Sg.E. You sit car come here, ah?

'Did you come here by car?'

Compare:

(13) Hokkien: lí che chhia lâi chit-tau ah?

you sit car come here QP

'Did you come here by car?'

Similar SVCs are also found in Caribbean creole languages, as part of a much wider range of serial verb constructions modeled on those of West African languages (Winford 1993, Migge 2003).

(14) a. Sranan Marinus tyari a buku go na wowoyo. Marinus carry DET book go LOC market

'Marinus took the book to the market.' 


$\begin{array}{ll}\text { b. Ewegbe } & \text { koku tso agbale-a yi asi-me } \\ & \text { Koku take book-DEF go market-inside } \\ & \text { 'Koku took the book to the market.' } \\ & \text { (Essegby \& Bruyn, to appear). }\end{array}$

We find similar cases of the transfer of L1 serial verb patterns into L2 interlanguage by classroom learners. Helms-Park (2003) discusses examples like the following, from the L2 English of elementary-level Vietnamese learners.

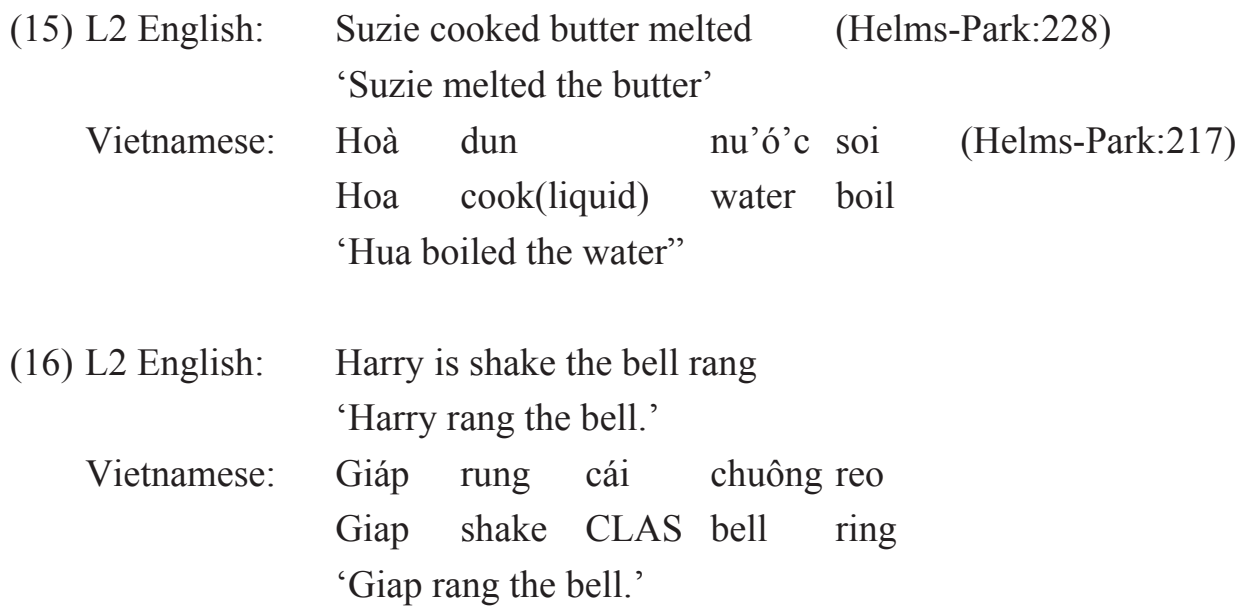

In attempting to produce L2 sentences with causative verbs, the Vietnamese learners are clearly transferring the lexicalization patterns of their L1 onto their L2 English, creating serial verb constructions similar to those in their L1. In these cases, this goes hand in hand with the transfer of the L1 argument structures. As Helms-Park" (2003:213) notes, this is a fairly common strategy in SLA, by which learners "treat TL verbs as though they had the lexico-semantic structure and accompanying argument structures of their ostensible L1 translation equivalents."

\subsection{Imposition and $L 1$ attrition}

As noted above, imposition is not confined to cases of SLA. It can occur in any situation of bior multilingualism where the dominance relationship between the languages changes. Bilinguals who gradually shift to an L2 and use it as their primary language often impose features of the L2 on their L1 to compensate for their loss of proficiency in the latter. A well-documented case of this is the variety of Spanish used by English-dominant bilinguals in Los Angeles (Silva-Corvalán 1998). They produce structures like the following:

$$
\begin{aligned}
& \text { (17) LA Spanish. Se lo dió p'atras } \\
& \text { 3sg.dat 3sg.accus gave back } \\
& \text { 'S/he gave it back to him/her.' } \\
& \begin{array}{lll}
\text { Gen. Spanish } & \text { se lo } & \text { volvió } \\
& \text { 3sg.dat 3sg.accus } & \text { returned } \\
& \text { 'S/he gave it back to him/her.' }
\end{array}
\end{aligned}
$$


Here, dar p'atras is a direct calque on the English expression give back, which is normally conveyed by volver 'to return' in General Spanish.

We find similar kinds of convergence in the attriting L1 of bilingual immigrant children for whom the L2 of a host community is becoming dominant. Matras \& Sakel (2007:855) provide the following example of English influence on a trilingual child's Hebrew and German:

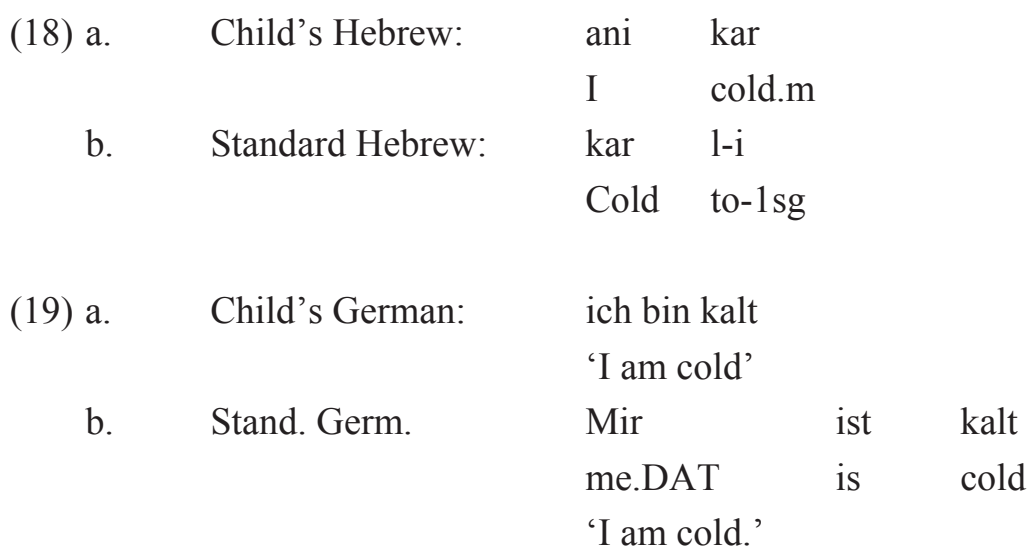

In both cases, the child employs a predicative adjective construction in which the experiencer role is mapped onto the subject on the model of English, instead of the respective Standard Hebrew and German constructions in which 'cold' is the subject and the experiencer is in oblique (dative) case. There are many other studies of similar kinds of convergence due to imposition from a newly dominant language on the attriting L1 of bilingual children.

Not surprising, similar convergence phenomena are well attested in the L1 performance of adult bilinguals who are shifting to a host community's language. For example, Savic'(1995) discusses how structural convergence toward English is reshaping the Serbian variety spoken by SerbianAmerican college students in areas such as word order and the expression of tense/aspect. Clyne (2003) describes various kinds of convergence toward English in the speech of Dutch and German immigrants in Australia. Among these are instances of convergence in word order as well as morphosyntax (the expression of past events with 'have' rather than 'be'), as shown in the following examples from German immigrants (2003:80):

$\begin{array}{cllll}\text { (20) Wir } & \text { haben } & \mathrm{zu} & \text { Schule gegangen } & \text { in Tarrington } \\ \text { we } & \text { AUX+have } & \text { to } & \text { school go }+\mathrm{PP} & \text { in Tarrington }\end{array}$

$\begin{array}{clll}\text { (21) Wir haben gegangen } & \mathrm{zu} & \text { Schule in Tarrington } \\ \text { we } & \text { have gone } & \text { to } & \text { school in Tarrington }\end{array}$

Compare Standard German:

(22) Wir sind in Tarrington zur Schule gegangen.

'We went to school in Tarrington'

Similar patterns are found in the speech of Dutch immigrants. Some speakers take convergence even further, producing utterances that look very much like English sentences partly relexified with 
Dutch words:
(23)Aus. Dutch
je heb te look voor een ander job
(Clyne:178)
(24) St. Dutch
je moet een andere baan gaan zoeken
you must an other job go seek
'You have to look for another job.'

Transfer of grammatical patterns is also common in cases where a community continues to preserve its ancestral language in the face of strong cultural pressure from a socially dominant language. For instance, Grecophone communities in Asia Minor Greek spoke a form of Greek that was so heavily influenced by Turkish, that it led Dawkins to make the famous pronouncement that "the body has remained Greek, but the soul has become Turkish" (Dawkins 1916:198). Turkish influence was pervasive and heavy in all domains of the language, lexicon, phonology, morphology and syntax. For example, the SOV order typical of Turkish is far more frequent in Asia Minor Greek (AMG) than other orders, by contrast with Modern Greek (MG). ${ }^{2}$

(25) a. AMG eto naiki eto to korits dhen do thelixen
that woman that the child didn't it

In copula constructions, the copula is frequently clause-final, as in Turkish.

$\begin{array}{rllll}\text { (26) a. } & \text { AMG } & \text { isy ena fikare } & \text { sai } \\ & & \text { you a } & \text { poor man are } \\ \text { b. } & \text { MG } & \text { eisai enas } & \text { ftochos anthropos } \\ & & \text { you-are a } & \text { poor man } \\ & \text { 'You are a poor man.' }\end{array}$

Janse (to appear) provides a rich and comprehensive account of Turkish influence on all aspects of the structure of Asia Minor Greek. Such influence has usually been treated as due to "structural borrowing" (Thomason \& Kaufman 1988), but both the nature of the changes and the sociolinguistic context of the contact suggest that imposition was the transfer type involved.

The above overview has shown that imposition is a quite general type of transfer that can be observed in contact situations where one language dominates the other in bilingual individuals' competence. We have also seen that the types of convergence phenomena that have been documented for past outcomes of language contact can also be found in contemporary situations of bilingualism. In all these cases, the results are due to processes of imposition that occurred under circumstances of language shift, with L1 features being imposed on an L2 in the course of SLA, and $\mathrm{L} 2$ features being imposed on the L1 as the former becomes the more dominant language. It also seems to be the case that imposition can occur even in cases of balanced bilingualism, where

\footnotetext{
${ }^{2}$ I am very grateful to Dimitris Kritsotakis for supplying Modern Greek translations of the Cappadocian Greek sentences.
} 
dominance relations between the languages are relatively equal. Van Coetsem (2000) refers to this as "neutralization", where either language can act as the source language, so that both borrowing and imposition can occur simultaneously. In these cases, it is particularly difficult to distinguish the effects of the two transfer types.

The findings above are compatible with Matras \& Sakel's (2007:849) observation that there are three different possible scenarios in which convergence (or what they call "pattern replication") can occur. These include situations in which a learner attempts to be creative in an L2; situations in which a learner reshapes L1 structures to accommodate to an external model; and situations in which balanced bilinguals level the structures of both languages. All such situations involve imposition as the transfer type that promotes convergence. In the following section, I provide further support for these scenarios from psycholinguistic studies of bilingualism, and suggest ways in which psycholinguistic models of language production might enrich our understanding of the dynamics of imposition.

\section{Language processing and production in bilinguals}

Hamers \& Blanc (2000) summarize a variety of psycholinguistic studies that show that "bilinguals do not process sentences in a way totally independent of their processing mechanisms in the other language" (2000:181). Such studies show that the degree of crosslinguistic transfer depends on the bilingual's degree of proficiency in the two languages. The general finding is that "the dominant language consistently caused more interlingual interference than the weaker language" (op.cit., 175). To take one example, a study of Chinese-English bilinguals in the US by Liu, Bates \& Li (1992) found that transfer patterns differed significantly depending on whether or not the speakers were born in the US, and on the age at which they became bilingual. Thus, childhood bilinguals who arrived in the US between the ages of 6-10 performed like monolinguals in both languages. By contrast, late bilinguals tended to transfer L1 strategies (e.g., word order in English, or animacy in Chinese) to their L2, while American-born childhood bilinguals tended to transfer L2 (English) strategies to their L1 (Chinese). The latter two tendencies correspond respectively to those we discussed earlier for L1 dominant bilinguals, and bilinguals whose L1 is undergoing attrition at the expense of an L2.

Studies of code-switching and other types of bilingual language production have also provided clear evidence that dominance relations between the languages are crucial to the kind of transfer that takes place. For instance, Bentahila \& Davies (1992) show that balanced Dutch/Moroccan Arabic bilinguals in Holland produce patterns of alternational or intersentential code switching that reflect their equal proficiency in both languages. On the other hand, bilinguals who are more proficient in Arabic use patterns of intrasentential code switching that involve insertion of Dutch lexical items into an Arabic morphosyntactic frame. Bentahila \& Davies are careful to point out that language dominance is only "one factor among others which is likely to influence a bilingual's language choice and communicative strategies" (1992:455). Studies by Clyne (2003) and others have also shown that patterns of code switching change drastically when speakers are losing proficiency in their L1 as they shift to another language, as in the case of Dutch and German immigrants in Australia. In the latter situation, as we saw earlier, we find a growing influence of the newly dominant L2 on the L1, leading to structural convergence of the latter toward the former.

Psycholinguists have attempted to account for these different types of language mixture by appealing to models of bilingual language production based on Levelt's (1989) model of monolingual language production. The basic aim of these models is to explain how, in the course of speech production, conceptual structures are mapped onto linguistic form. It is generally agreed that three types of mental processes are involved: conceptualization processes that specify which concepts are to be expressed verbally; formulation processes that select appropriate lexical items and construct the syntactic and phonological structure of the utterance; and articulation processes 
that realize the latter as overt speech (Roelofs 1993:108). The basic outline of the model is shown in figure 1.

Figure 1. A simplified model of language production.

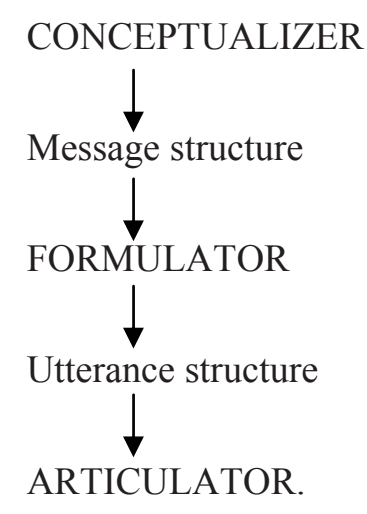

As Levelt (1993:5) explains, conceptual structures are the preverbal messages that form the input to the Formulator, "whose task it is to map the message onto linguistic form." The final output of the Formulator is "a phonetic plan that can be executed by the articulatory motor system" (ibid.). The formulator therefore involves two processes: grammatical and phonological encoding. Only the first of these concerns us here. Levelt explains: "Grammatical encoding takes a message as input, retrieves lexical items from the mental lexicon, and delivers a surface structure as output" (ibid.). Lexical retrieval involves, first, accessing the lemmas associated with the relevant lexical item, and second, selecting the item's form specification or lexeme as it is stored in the mental lexicon.

Levelt (1993:4) represents the procedure of lexical access as shown in Figure 2:

Figure 2. An outline of lexical access in speech production

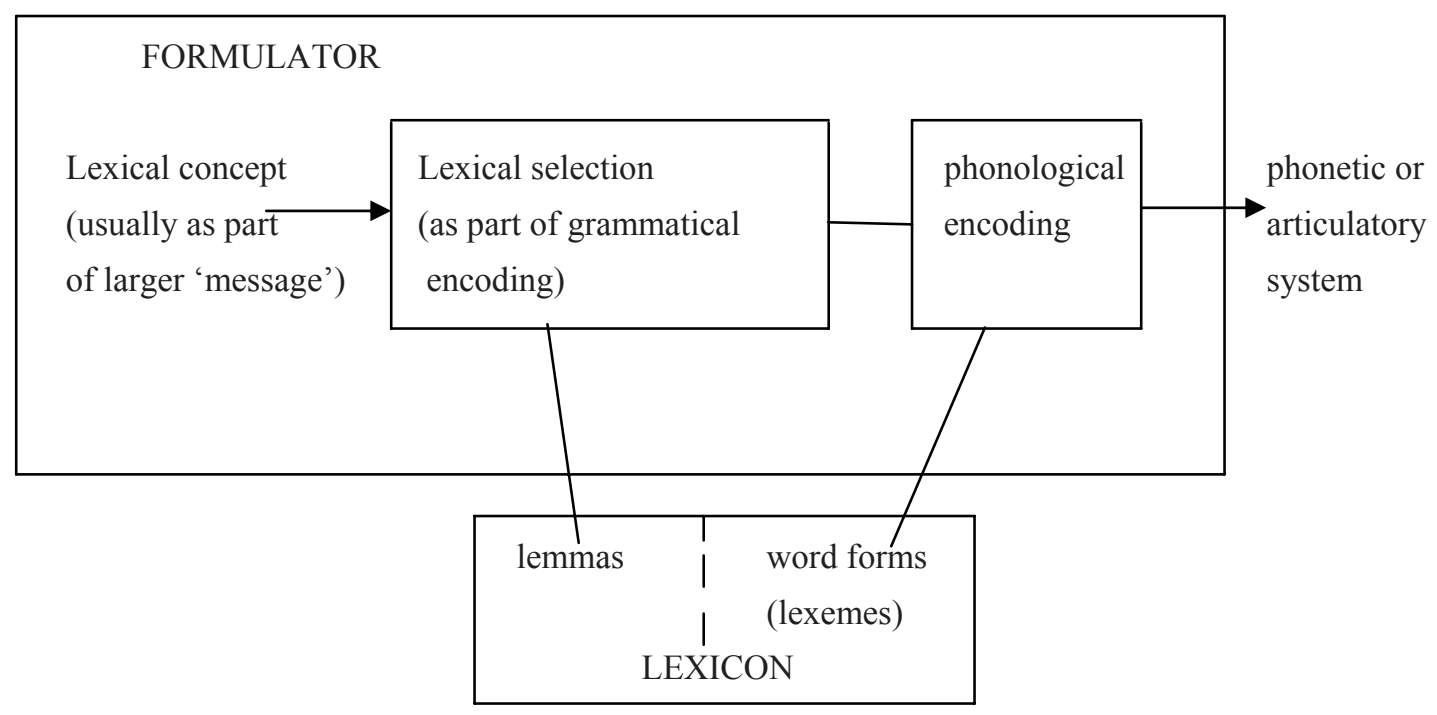

Lemmas contain information about the semantic, syntactic and other grammatical properties of the relevant lexical item. The crucial premise of the model is that "lexical selection drives 
grammatical encoding" (ibid.); in other words, "the lexicon is an essential mediator between conceptualization and grammatical .. encoding" (Levelt 1989:181). This assumption, referred to as the "lexical hypothesis", draws on lexicalist approaches to syntax which view the syntactic behavior of verbs as directly related to their semantic composition (e.g, Jackendoff 1990, 1997; Bresnan 1982). Jackendoff explains that "the formal role of lexical items is not that they are 'inserted' into syntactic derivations, but rather that they license the correspondence of certain (near)-terminal symbols of syntactic structure with phonological and conceptual structures" (1997:89-90). Hence, as Pienemann (1999:51) notes ".....recognition and/or production of the constituent structure of a sentence relies crucially on the syntactic sub-categorization of lexical material."

In short, lemmas activate or trigger syntactic procedures that correspond to their syntactic specifications. Thus, a verb will trigger construction of a VP, a preposition the construction of a PP, etc. For example, selection of the lemma for the verb sell will trigger construction of a clause with three arguments, agent, theme, and goal, which are mapped onto the grammatical functions of subject, object and indirect object respectively.

We will see that lemma access is fundamental to the kinds of crosslinguistic transfer that are associated with imposition. For instance, in cases of SLA, incomplete acquisition of lemmas associated with L2 lexemes may trigger imposition of lemmas associated with corresponding L1 lexemes. On the other hand, in cases of language attrition, loss of command of L1 lemmas may lead to imposition of L2 lemmas on L1 lexemes. The first of these scenarios applies in the case of creole formation, which I will examine in the following section.

\section{Recent models of creole formation}

In creole formation, just as in second language acquisition, learners tend to appeal to L1 knowledge to compensate for their lack of proficiency in their L2. This is reflected in their L2 production, which depends to varying degrees on the grammatical encoding procedures of their L1, which is dominant. Previous researchers have tried to account for this kind of transfer using different models. Of these, the ones most relevant to the present discussion are the Abstract Level Model of Myers-Scotton (2002) and the Relexification Hypothesis of Lefebvre \& Lumsden (1994), and their associates. Each of these has its own advantages, and both are compatible with the psycholinguistic approach advocated here.

Lefebvre \& Lumsden's chief contribution to our understanding of creole formation is the Relexification Hypothesis, which is essentially a model of how creole lexical entries are created. Lumsden (1999:130-131) defines relexification as a mental process in which

A person who already has a native language may create a new vocabulary of lexical categories (i.e., nouns, verbs, adjectives, etc.) by linking the semantic and syntactic representations of his native language lexicon with new phonological representations that are derived from the phonetic strings of a target language.

Lefebvre (1998:16) represents the process as follows: 
Figure 3. Lefebvre's representation of relexification.

\section{L1 lexical entry}

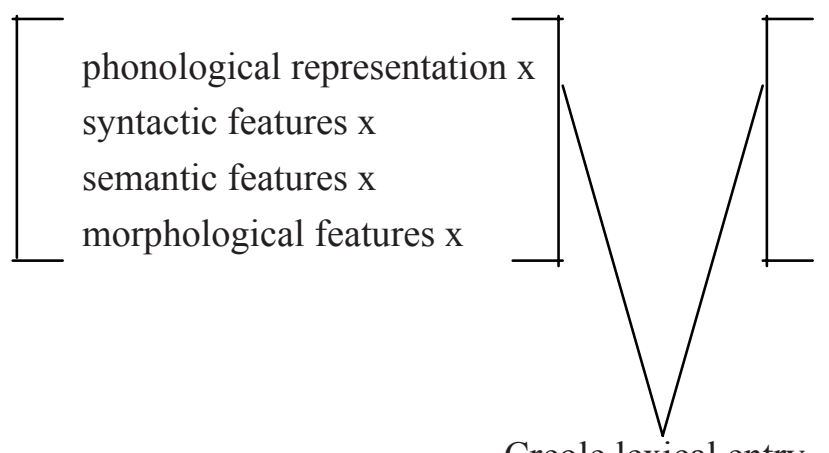

Creole lexical entry

\section{L2 lexical entry}

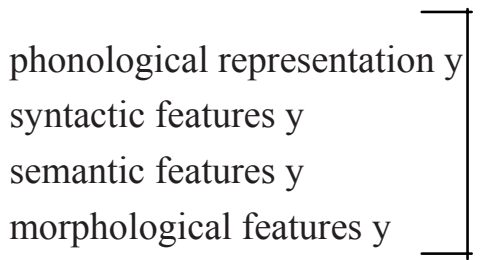

$\left[\begin{array}{l}\text { phonological representation } \mathrm{y} \\ \text { syntactic features } \mathrm{x} \\ \text { semantic features } \mathrm{x} \\ \text { morphological features } \mathrm{x}\end{array}\right]$

The key point in this representation is that creole lexical entries contain lexemes derived from the superstrate language, but their syntactic and semantic properties -their lemmas, in short - are derived from the substrate language(s). As it stands, the representation is somewhat misleading, since it implies that superstrate lexical entries in their entirety were available to creole creators. However, Lefebvre makes it clear that, in the creation of creoles such as Haitian Creole, learners either had no access to this information, or if they did, they did not use it in creating the new lexical entry (1998:17). The only "trigger" required for relexification in these cases is semantic overlap between the semantic representations of the superstrate and substrate entries (1998:16). Lefebvre further argues that relexification is central to the shaping of creole grammar, since "most of the information that distinguishes particular grammars is stored in the lexicon" (1998:40). This suggests that the RH assumes the lexicalist hypothesis, which in turn underlies the psycholinguistic view that lexical selection drives grammatical encoding, as discussed above.

The RH, then, is compatible in several respects with the view presented here that imposition is one of the major psycholinguistic mechanisms behind the creation of creole grammar. First, the RH treats creole formation as a case of second language acquisition in which grammatical properties of substrate lexical entries are transferred to superstrate-derived lexical items. Second, the RH can be interpreted in psycholinguistic terms to mean that the lemmas associated with lexemes in the linguistically dominant language (the substrate) are assigned to lexemes of the less dominant L2 (the emerging creole). Third, as just indicated, the RH assumes a lexicalist view of syntax, which accounts for why the syntactic encoding procedures triggered by substrate-derived lemmas produce creole structures quite similar to those of the substrate.

Lefebvre and her associates provide many examples of grammatical structures in Haitian Creole that are due to the workings of relexification, where Fongbe in particular provides the lemmas assigned to French-derived lexemes. Some of these structures involve the transfer of Fongbe subcategorization frames to $\mathrm{HC}$ verbs. For instance, verbs like voye 'send' assume the subcategorization properties of the corresponding Fongbe verbs, e.g., $t \dot{\varepsilon}$ 'send' as in the following examples (1998:284): 


$\begin{array}{rlllll}\text { (27) a. } & \text { Fongbe: } & \text { é } \quad \text { tè } \quad \text { kàn } & \text { sè-dó } & \text { mari } \\ \text { b. } & \text { Haitian: } & \text { Li } \text { voye telegram } & \text { bay } & \text { Mari } \\ & & \begin{array}{l}\text { he send telegram } \\ \text { 'He sent a telegram to Mary.' }\end{array} & \text { send/give } & \text { Mary } \\ \text { c. } & \text { French: } & \begin{array}{l}\text { Il a envoyé un télégramme à Marie. } \\ \text { 'He sent a telegram to Mary.' }\end{array}\end{array}$

Lefebvre (1998:284) argues that, in these and other cases, "the Case properties of the Haitian verbs.. should be considered as having been transferred from the substratum language into the creole through relexification."

The relexification model provides a reasonable hypothesis about how various aspects of creole grammar originated. But the major justification that Lefebvre provides for it comes simply from a comparison of substrate and creole grammars. It does not really provide an explanation for the psycholinguistic mechanisms involved in the relexification process.

Myers-Scotton's (2002) Abstract Level Model attempts to provide such an explanation by appealing to psycholinguistic models of language production. Certain premises of this model are in fact quite similar to those of the RH as they apply to creole formation. For instance, Myers-Scotton also treats creole formation as a kind of second language acquisition, and also accepts that the superstrate languages provided lexical elements while the substrate languages provided the grammatical frame of the creole. Myers-Scotton's model also appeals directly to the lexicalist hypothesis to account for how grammatical encoding is driven by the lexicon in creole formation. Despite these similarities, Myers-Scotton (2002:290) criticizes the RH for lacking specifics of the "mental processes" that motivate the creation of creole grammar. She chaims that her own model provides the "theoretical motivation" that the RH lacks.

Myers-Scotton treats creole formation as an outcome of what she calls "convergence," which she defines as as "largely a one-way phenomenon .... [that] involves the grammar and lexicon of a source language ... impinging on another language" (2002:172). It is clear that this corresponds to imposition. To account for the process of convergence, she proposes an Abstract Level Model, which draws on the psycholinguistic models of language production discussed above. According to Myers-Scotton's model, all lemmas in the mental lexicon include three levels of abstract lexical structure, namely, lexical-conceptual structure (semantic and pragmatic information); predicateargument structure (the mapping of thematic structure onto syntactic relations), and morphological realization patterns (surface realizations of grammatical structure) (2002:194). Myers-Scotton argues that, in cases of convergence, one or more of these levels from a lexical entry in one language can be split and recombined with levels in another language (2002:99).

As a mechanism, convergence is the process that promotes a splitting of abstract lexical structure in one variety, and its combining with such abstract lexical structure from another variety, often resulting in a restructuring of grammatical relations and even surface-level grammatical morphemes from the stronger group in the equation... (2002:164)

This process of what might be called "lemma reconstruction" shares much in common with Lefebvre's model of relexification, particularly with regard to the idea that creole lexical entries combine superstrate-derived lexemes with substrate-derived lemmas. What Myers-Scotton adds to this is insight from psycholinguistic models into what she calls "the abstract architecture of language competence and language production" (2002:290). Myers-Scotton's main contribution is the idea that the lemmas associated with creole lexical entries are themselves the result of the splitting and recombining of different levels of the abstract structures associated with lexical entries in the superstrate and substrate languages. This approach is quite compatible with the view 
presented here that imposition plays a major role in the emergence of creole lexical entries, and by extension, creole grammar.

Despite this important insight into creole formation, Myers-Scotton unfortunately does not illustrate in detail how specific creole structures arise from the splitting and recombining of abstract lexical structures. Like Lefebvre, she is content to show how certain creole structures display similarity to structures in their relevant substrates. It seems reasonable, then, that we should attempt to explain the way processes of lemma reconstruction contribute to the emergence of specific creole structures. As I have argued, the transfer type underlying these processes is imposition. In the following section, I attempt to show how a psycholinguistic approach such as advocated by MyersScotton can further our understanding of the way this mechanism works in creole formation, as well as in related types of contact-induced change such as language attrition.

\section{Mechanisms of imposition in creole formation}

The insights of the psycholinguistic models discussed above suggest that we can view imposition as a type of cross-linguistic influence in which production processes of a dominant source language are transferred to the production of a recipient language in which speakers are less proficient. Such influence can occur at various levels of the language production process, for instance, at the level of lexicalization patterns (how conceptual structures are split up into chunks that can be verbalized), at the level of word order, and at the level of access to lemmas, which as already noted contain information about the semantic, grammatical and morphological properties of lexical items. For present purposes, I focus on the level of lemma access or activation at the level of the Formulator, whose task is to "select appropriate lexical items and integrate them into a syntactic structure or grammatical form" (Bierwisch \& Schreuder 1993:26).

We can assume that, in the early stages of creole formation, just as in the early stages of second language acquisition in general, learners have not yet acquired all of the grammatical information associated with the L2 lexemes they can produce. As Pienemann (1999:50) puts it, learners have not indexed newly acquired lexical items to their lemmas, hence they cannot use the L2 lemmas as a basis for producing larger syntactic structures. So when the need arises, they tend to fall back on the lemmas associated with semantically equivalent items in their L1s, to supply the information necessary for them to initiate more complex syntactic procedures. If they have continuous and adequate access to the L2, they gradually acquire the relevant lemma information and learn how to reproduce L2 syntactic procedures. On the other hand, if access to the L2 is restricted, or if the L2 input consists only of highly simplified structures or pidginized varieties, as in many cases of creole formation, then learners impose L1 lemmas on the L2 lexemes. This is why, in many cases of creole formation, the learner's L1, as the dominant language, controls language production processes at the level of the Formulator, thus determining lexicalization patterns, word order, subcategorization, complementation, and other procedures. For imposition to take place in these cases, it is sufficient for learners merely to have access to the semantics of an L2 lexical item, and its syntactic category. Similarity between the L2 item and a corresponding L1 item in these respects is all that is needed to trigger imposition of the L1 lemma on the L2 item. This is similar to the position taken by Lefebvre (1998:17) and Myers-Scotton (2002).

We can illustrate this with reference to some of the cases of imposition of syntactic patterns which we illustrated in section 3. Serial verb constructions are a good case in point. Let us say, for instance, that a speaker of a newly-emerging creole wishes to produce the equivalent of the following:

(28) They are hauling the boat to the river 
Let us further assume that the speaker is familiar with the verb haul, but not with all of its syntactic properties. The easiest solution to this would be to rely on the information contained in the lemma of the L1 equivalent of haul, and use it to produce the desired utterance. This would result in creole directional SVCs like the following, from Pamaka, which mirrors its counterpart in Wacigbe, one of the Gbe substrate languages (Migge 2003:96).

(29)PM

(30) Wacigbe

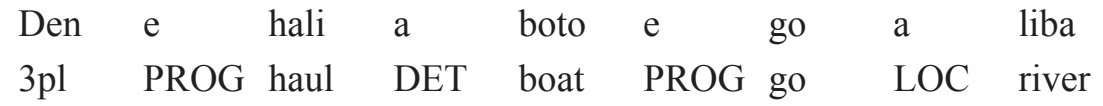

'They are hauling the boat to the river.'

$\begin{array}{lllllll}0 & \text { la } & \text { don } & \text { saki } & \text { a } & \text { yi } & \text { afə-mə } \\ 3 \text { pl } & \text { FUT } & \text { drag } & \text { bag } & \text { DET } & \text { go } & \text { house-in }\end{array}$

'They'll drag the bag to the house.'

In keeping with the lexicalist hypothesis, structures like these arise when the subcategorization properties of substrate motion or transfer verbs like don are imposed on superstrate lexical items such as hali. Like don, hali requires that its Theme be mapped onto a direct object, while its Goal must be expressed by a directional VP complement headed by a verb like go, which indicates the direction of the transfer. This might be represented as follows:

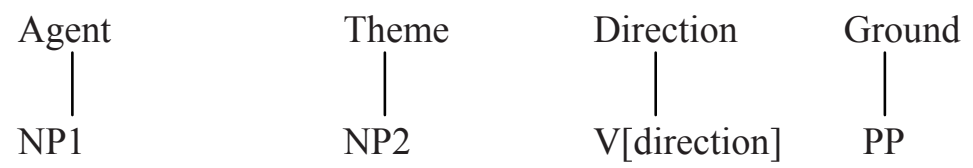

The syntactic rules that apply here may be represented roughly as follows:

$$
\begin{aligned}
& \mathrm{S} \rightarrow \mathrm{NP} \quad \mathrm{VP} \\
& \mathrm{VP} \rightarrow \mathrm{V} \text { [motion] } \quad \mathrm{NP} \quad \mathrm{V} \text { [direction] } \quad \mathrm{PP}
\end{aligned}
$$

The mapping of argument structure onto syntactic form is identical in the creole and Gbe, but quite different from what we find in English. The Surinamese creoles have a wide range of such directional VPs, headed by other verbs such as kom 'come,' gwe 'go away,' komopo 'come up,' komoto 'come out,' etc., which also indicate direction, and are modeled on substrate equivalents.

Situations of attrition also provide examples of the transfer of argument structure and subcategorization properties from an L2 that has become dominant over an L1. In L.A. Spanish, for instance, we find structures like the following in the speech of English-dominant bilinguals (SilvaCorvalán 1998:233).

(32) a. LA Spanish. Yo gusto eso

I like-1s that

b. Gen Span. A mi me gusta eso.

To me pro please- $3 \mathrm{~s}$ that

'I like that.' 
The LA Spanish example is a case where the syntactic properties of the English verb like have been imposed on the Spanish verb gustar. In General Spanish, gustar has a Theme that is mapped to a subject and an Experiencer that is mapped to an indirect object. This mapping can be represented as follows:

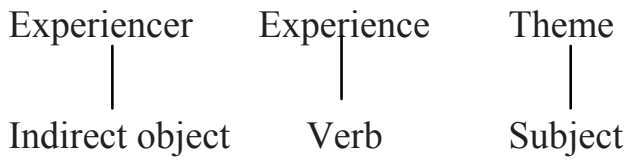

In LA Spanish, by contrast, gustar adopts the subcategorization properties of English like, and replicates the latter's mapping of thematic roles onto syntactic form, in which the Experiencer role is mapped onto the subject and the Theme onto the object. The following illustrates:

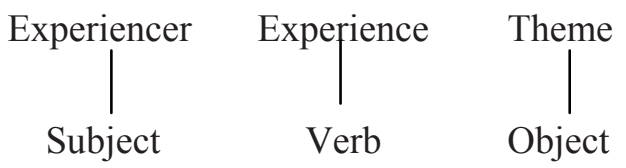

Space does not permit illustration of further examples of transfer due to imposition at other levels of structure. The transfer of word order patterns, as we saw in section 3, is also quite common in cases of SLA, as well as in cases of attrition. Similarly, the transfer of other aspects of grammar, such as grammatical categories, complementation patterns and so on, has also been well documented in the literature on contact-induced change. I have suggested that such cases of transfer can be accounted for in terms of the concept of imposition, which is ultimately related to the psycholinguistic mechanisms involved in bilingual language production. Matras \& Sakel (2007:835) put it well when they suggest that bilinguals aim at maximum syncretization of processing operations in their two languages, "allowing speakers to apply similar mental organization procedures to propositions in both languages of their repertoire." In situations where the dominance relationship between languages is unequal, the simplest solution is to use the processing procedures associated with the more dominant language, in producing the less dominant language. This is what accounts, to a large extent, for the similarities in the kinds of transfer due to imposition that we have observed in the various contact situations examined in this paper. Ultimately, it is true that the processes of change observed in creole formation are not different in kind from those found in other cases of language contact where one of the languages is dominant over the other.

\section{References}

Aikhenvald, Alexandra. 2002. Language contact in Amazonia. Oxford: Oxford University Press.

Andersen, Roger W. 1983. Transfer to Somewhere. In S. Gass \& L.Selinker (eds.), Language Transfer in Language Learning, 177-201. Rowley, Mass.: Newbury House.

Andersen, Roger W. 1990. Models, processes, principles and strategies: second language acquisition inside and outside the classroom. In Bill VanPatten \& James F. Lee (eds.) Second Language Acquisition/Foreign Language Learning, 45-66. Philadelphia: Multilingual Matters Ltd. 
Arends, Jacques. 1995b. Demographic factors in the formation of Sranan. In Jacques Arends (ed.), The early stages of creolization, 233-85. Amsterdam: John Benjamins.

Bailey, Charles-James and K. Maroldt. 1977. The French lineage of English. In Jürgen M. Meisel (ed.) Langues en contact-pidgins-créoles-languages in contact, 21-53. Tübingen: TBL Verlag, G. Narr.

Bakker, Peter. 2003. Mixed languages as autonomous systems. In Yaron Matras \& Peter Bakker (eds.), The Mixed Language Debate: Theoretical and empirical advances, 107-150. Berlin New York: Mouton de Gruyter.

Bao, Zhiming. 2005. The aspectual system of Singapore English and the systemic substratist explanation. Journal of Linguistics 41:237-267.

Bentahila, Abdelâli \& Eirlys E. Davies. 1992. Code-switching and Language Dominance. In R. J. Harris (ed.), Cognitive processing in bilinguals, 443-458. Amsterdam - New York: Elsevier Science Publishers.

Bierwisch, Manfred \& Robert Schreuder. 1993. From concepts to lexical items. In Willem J.M. Levelt (ed.), Lexical Access in Speech Production, 23-60. Cambridge MA - Oxford UK: Blackwell.

Bresnan, Joan (ed.) 1982. The mental representation of grammatical relations. Cambridge Mass.: MIT Press.

Clyne, Michael. 2003. Dynamics of language contact. Cambridge: Cambridge University Press.

Coelho, F. A. 1880-1886. Os dialectos românicos ou neolatinos na África, Asia, e América. Bolletim da Sociedade de Geografica de Lisboa. (Republished in J. Morais-Barbosa (ed.) 1967, Estudos linguísticos crioulos. Lisbon: Academia Internacional de Cultura Portuguesa.

Da Cruz, Maxigbeme. 1995. Aspectual verbs fó, vó 'finish' in Fongbe. The Linguistic Review 12:361-380.

Dawkins, R. M. 1916. Modern Greek in Asia Minor: a study of the dialects of Silli, Cappadocia and Phárasa with grammars, texts, translations and glossary. Cambridge: Cambridge University Press.

Essegbey, James \& Bruyn, Adrienne. To appear. Moving into and out of Sranan. In Hubert Cuyckens, Adpositions of movement. Amsterdam: John Benjamins.

Gumperz, John J. \& Robert Wilson. 1971. Convergence and creolization: a case from the IndoAryan/Dravidian border in India. In Dell Hymes (ed.), 151-67. Cambridge: Cambridge University Press.

Hamers, Josiane F. \& Michel H. Blanc. 2000. Bilinguality and Bilingualism. $2^{\text {nd }}$ edition. Cambridge: Cambridge University Press.

Harris, John. 1984. Syntactic variation and dialect divergence. Journal of Linguistics 20:303-327.

Heath, Jeffrey. 1984. Language Contact and Language Change. Annual Review of Anthropology 13: 367-384. 
Heine, Bernd \& Tania Kuteva. 2005. Language Contact and Grammatical Change. Cambridge: Cambridge University Press.

Helms-Park, Rena. 2003. Transfer in SLA and Creoles: causative serial verbs. Studies in Second Language Acquisition 25: 211-244.

Hesseling, Dirk Christiaan. 1897. Het Hollandsch in Zuid-Afrika. De Gids 60.1:138-162. (Reprinted in English in Dirk Hesseling (1979) On the origin and formation of creoles: a miscellany of articles. Ann Arbor: Karoma.Hussainmiya.

Hymes, Dell (ed.). 1971. Pidginization and creolization of languages. Cambridge: Cambridge University Press.

Jackendoff, Ray. 1990. Semantic structures. Cambridge Mass.: MIT Press.

Jackendoff, Ray. 1997. The Architecture of the Language Faculty. Cambridge Mass.: MIT Press.

Janse, Mark. To appear. The Cappadocian Dialect. In Christos Tzitzilis. The Modern Greek Dialects, Thessaloniki: Institute of Modern Greek studies. 2005.

Johanson, Lars. 2000. Linguistic convergence in the Volga area. In D.G. Gilbers, J. Nerbonne, \& J. Schaeken (eds.), Languages in Contact (Studies in Slavic and General Linguistics 28), 165 178. Amsterdam - Atlanta GA: Rodopi.

Johanson, Lars. 2002. Structural factors in Turkic language contacts. London: Curzon.

Keesing, Roger. 1988. Melanesian Pidgin and the Oceanic Substrate. Stanford: Stanford University Press.

Lefebvre, Claire. 1998. Creole genesis and the acquisition of grammar. Cambridge: Cambridge University Press.

Lefebvre, Claire. 2001. The interplay of relexification and leveling in Creole genesis and development. Linguistics 39:371-408.

Lefebvre, Claire \& John S. Lumsden. 1994. Relexification in creole genesis. Paper read at the MIT Symposium on the role of relexification in creole genesis: The case of Haitian Creole.

Levelt, Willem. 1989. Speaking: from intention to articulation. Cambridge, Mass: MIT Press.

Liu, H., E. Bates \& P. Li. 1992. Sentence processing in bilingual speakers of English and Chinese. Applied Psycholinguistics 13:451-484.

Loveday, Leo J. 1996. Language Contact in Japan: A Socio-linguistic History. Oxford: Clarendon Press.

Lumsden, John. 1999. Language acquisition and creolization. In Michel DeGraff, Language creation and language change: Creolization, Diachrony and Development, 129-157. Cambridge, Mass: MIT Press.

Matras, Yaron \& Jeanette Sakel. 2007. Investigating the mechanisms of pattern replication in language convergence. Studies in Language 31.4:829-865.

Meshrie, Rajend \& Timothy T. Dunne. 1990. Syntactic variation in language shift: The relative clause in South African Indian English. Language Variation and Change 2.1:31-56. 
Migge, Bettina. 2003. Creole Formation as Language Contact. Amsterdam: John Benjamins.

Myers-Scotton, Carol. 2002. Contact Linguistics: Bilingual encounters and grammatical outcomes. Oxford: Oxford University Press.

Odlin, Terence. 1990. Word Order Transfer, Metalinguistic Awareness, and Constraints on Foreign Language Learning. In Bill VanPatten \& James F. Lee, Second Language Acquisition/Foreign Language Learning, 95-117. Philadelphia: Multilingual Matters.

Pienemann, Manfred. 1999. Language Processing and Second Language Development: Processability Theory (Studies in Bilingualism 15). Amsterdam: John Benjamins.

Roelofs, Ardi. 1993. A spreading-activation theory of lemma retrieval in speaking. In Willem J.M. Levelt (ed.), Lexical Access in Speech Production, 107-142. Cambridge MA - Oxford UK: Blackwell.

Sabban, Annette. 1984. Investigations into the Syntax of Hebridean English. Scottish Language 3:532.

Savić, Jelena M. 1995. Structural convergence and language change: Evidence from Serbian/English code-switching. Language in Society 24.4:475-492.

Schuchardt, Hugo. 1882. Kreolische Studien I. Ueber das Negerportugiesische von S. Thomé (Westafrika). Sitzungsberichte der kaiserlichen Akademie der Wissenschaften zu Wien 101.2: 889-917.

Schuchardt, Hugo. 1883. Kreolische Studien V. Ueber das Melaneso-englische. Sitzungsberichte der kaiserlichen Akademie der Wissenschaften zu Wien 105.1:151-161. (Reprinted in English in Schuchardt 1979, The ethnography of variation: selected writings on pidgins and creoles, edited and translated by Thomas L. Markey. Ann Arbor: Karoma, 18-25.

Siegel, Jeff. 2000. Substrate influence in Hawai'i Creole English. Language in Society 29:197-236.

Silva-Corvalán, Carmen. 1998. On borrowing as a mechanism of syntactic change. In Armin Schwegler, Bernard Tranel \& Myriam Uribe-Etxebarria (eds.), Romance Linguistics: Theoretical Perspectives, 225-246. Amsterdam: John Benjamins.

Southworth, Franklin C. 1971. Detecting prior creolization: an analysis of the historical origins of Marathi. In Dell Hymes (ed.), 255-273.

Thomason, Sarah G. \& Terrence Kaufman. 1988. Language Contact, Creolization and Genetic Linguistics. Berkeley: University of California Press.

Thurston, William R 1987. Processes of change in the languages of Northwest New Britain. Pacific Linguistics Series B, No. 99. Dept. of Linguistics, Australian National University, Canberra, Australia.

Van Coetsem, Frans. 1988. Loan phonology and the two transfer types in language contact. Dordrecht: Foris.

Van Coetsem, Frans. 2000. A general and unified theory of the transmission process in language contact. Heidelberg: Universitätsverlag, C. Winter.

Weinreich, Uriel. 1953. Languages in Contact. The Hague: Mouton. 
Winford, Donald. 1993. Predication in Caribbean English Creoles. Amsterdam: John Benjamins.

Winford, Donald. 2003. An Introduction to Contact Linguistics. Oxford: Blackwell.

Winford, Donald \& Bettina Migge. 2007. Substrate influence on the emergence of the TMA systems of the Surinamese creoles. Journal of Pidgin and Creole Languages 22.1:73-99. 
Journal of language contact - THEMA 2 (2008) www. jlc-journal.org 


\section{EMPIRICAL APPROACHES, APPLICATIONS AND DEVELOPMENTS}


Journal of language contact - THEMA 2 (2008) www. jlc-journal.org 